THE LANCET, APRIL 8, 1865.

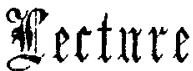

ON

\section{THE USE OF THE LARYNGOSCOPE.}

By E. H. SIEVEKING, M.D.,

PHYSICIAN IN ORDINARY TO THE PRINCE OF WALES, AXD TO ST. MARY'S HOSPITAL.

THE more we remove our means of diagnosis from the range of speculation, and reduce them to direct demonstration, the more precise and definite will be the treatment which we shall be able to employ for the removal of disease. The general aim of all modern observers has been to improve this department of our science. It has been done to so great an extent that complaints have even been raised that the healing of disease has come to be regarded by the physician as of less moment than its recognition. Clearly the two ought to go hand in hand, and I for one do not think it would be difficult to show that they have done so more than the cavillers seem disposed to admit. But whatever view we may take on the subject, we shall certainly agree as to this, that before we apply our remedies we must know the enemy we have to deal with. Disease being an aberration from those healthy states of furtction and of the tissues with which we are rendered familiar by anatomy and physiology, we cannot determine the mode in which and the means by which the morbid condition shall be removed, unless we are first enabled to determine what function or what tissue is involved. We are compelled by the state of science to deal with one or two specific remedies - that is, remedies whose action we can reduce to no simpler proposition than the statement that they cure certain diseases. But even then we must make sure in the first instance that we have the special disease to deal with for which we know the remedy empirically, and we leave to future inquirers to determine the exact mode in which that remedy operates. Supposing you see a person suffering from the rigors ushering in an attack of inflammation of the lungs. If you hastily jump to the conclusion that he is labouring under a paroxysm of ague, and administer a large dose of quinine, you commit the very error against which $I$ am protesting. You forget that the symptom for which you prescribe is but a general expression of the sympathy of the nervous and vascular systems with a local affection, and neglect to use the various means at your disposal to determine what that consists in. A proper inquiry would lead you to a precise result, which in its turn would indicate the employment of very different treatment. I will not illustrate further these general remarks on the importance of a correct diagnosis by a reference to diseases of the thorax, of the kidneys, of the nervous centres, for which modern inquirers have done so much. Your own observations at the bedside will, I trust, afford you daily suggestions as to the paramount necessity of using all the means at your disposal to determine accurately the morbid conditions before you.

The special object I now have in view is to urge upon you the importance of a new method of investigating a class of diseases which until very recently have belonged entirely to the range of speculation. The diseases themselves, it is true, have been tangible enough, but the uncertainty that surrounded them lay in the poverty of our means to discriminate the various conditions giving rise to but a limited class of symptoms. This opprobrium medicince is now removed, and we may say that diseases of the vocal cords and their appendages are lit up not only metaphorically but literally, in such a way as to add one more to the triumphs of science over darkness and ignorance. Before the introduction of the laryngoscope we might guess at the condition of the larynx, but nervousness, hysteria, laryngitis, laryngeal phthisis, and other terms, were used, according to the bias of the speaker, rather as a cloak for ignorance than as an indication of actual knowledge. The laryngoscope, by enabling us to look at the vocal cords, to watch their mode of action, to see whether they are discoloured or eroded, whether there is want of symmetry and loss of tone, whether there is tumefaction in the vicinity, whether there is a growth on or near the cords, gives us an amount of information which is of extreme value, both positively and negatively, in determining No. 2171. the presence or absence of disease, and the bearing of laryngeal symptoms upon morbid conditions at a distance. Let me explain my meaning more fully by considering the value of the most prominent symptom of laryngeal disease-aphonia, or loss of voice. Every tissue that enters into the formation of the vocal organs may be morbidly affected so as to induce a greater or less modification of the voice, but there is no modification of this symptom, and no combination into which it enters with other symptoms, which enables the physician positively to say what it is due to, unless by the aid of the laryngoscope. Pain and tenderness often indicate the seat and nature of a disease, but in the case of the larynx they are very commonly absent, even where there is serious disease. Dyspnœa, as you know, is a symptom of so many morbid conditions that it but rarely helps us in determining the share the larynx has in its production.

One of the first cases of laryngeal disease which I ever examined with the laryngoscope was one in which its value was well illustrated. The case was that of a coachman in whom the complex symptoms appeared to indicate the presence of subclavian aneurism, and the physical signs seemed to receive corroboration from the fact of complete aphonia being present. Pressure of the aneurism upon the recurrent laryngeal nerve would account for the aphonia. The laryngoscope, however, removed this supposed symptom of aneurism from the list, inasmuch as it proved to be due to the presence of large epithelial growths on the vocal cords-growiths the frequency of which was not suspected until the laryngoscope was brought to carry light into this hitherto dark recess of the human economy. Or take another case. I am frequently consulted by a lady who for above three years has been afflicted with complete aphonia. It appeared to have been brought on in the first instance by cold, and the patient was treated by various physicians on the supposition that she was labouring under laryngitis. At all events heroic remedies, such as a collar of blistering plaster and the like, were employed, under the direction of men of great authority in our profession. But the laryngoscope failed to detect any trace of inflammatory or degenerative action; there was no visible evidence of any disease of the vocal cords, and it became necessary to look for the cause of the symptom elsewhere. You will observe the very opposite significance of the laryngoscopic investigation in the two cases mentioned. In the one, the patient hal no chance of recovery without local surgical interference; in the other, all local treatment would - as it did-prove unavailing, because there was no disease within the larynx upon which causties, sedatives, stimulants, or any other agents could be brought to bear. I remember another very striking illustration-an hospital patient in whom there were what appeared to be urgent symptoms of acute laryngitis. They had supervened suddenly, and the diagnosis received confirmation from the fact of her having on a former occasion been tracheotomised for what she stated to have been the same symptoms. You may conceive my astonishment when I found the larynx to be perfectly patulous, the vocal cords presenting that peculiar pearly whiteness which characterizes them in health, and a complete ab sence of all local evidence of laryngitis. Again, in phthisis, how frequently do we meet with more or less aggravated aphonia, in which the treatment to be pursued must vary materially according to the exact lesion, which in many cases -I should say the majority-does not demand local application, unless it be for the purpose of showing the dexterity of the operator. If you find, as in a case of which the notes are before me, that in a phthisical aphonia the vocal cords and adjacent parts are perfectly normal, you would justly conclude that the general debility due to the discuse had also involved the vocal organs, and that, therefore, general treatment would alone be required.

Let us now briefly consider the laryngosiope itself-what it is to do, and what it enables the physician to do. You may have read in that charming book by Dr. John Brown, the "Horæ Subsecivæ," that Opie was asked how he came to paint as he did, and that he replied "Wi' brains, sir." The laryngoscope - to apply the same principle in medicine - requires "brains" in the observer as the canvas and easel do in the painter. But it requires no more brains nor any greater aptitude than the other instruments that we are constantly using; and it is on the ground of it deserving the attention of every medical man in ordinary practice that $I$ hare asked you to listen to these remarks. I consider that the laryngoscope ought to form as much a part of your apparatus as the stethoscope ; it requires very much less training, in fact, than that instrument and I have generally found that the gentlemen to whom I have demonstrated the use of the instrument conld 
empioy it with ease after the first lesson. I do not doubt that you will readily admit that there is no magic in its application. It is necessary that you should know the anatomy of the parts and the simplest laws of optics, and you will then easily realize all your anticipations. Several of you have already seen in the cases that $I$ have brought under your notice, and by demonstrations upon yourselves and me, that there is no mystery attaching to it. One of the patients alluded to $(\mathrm{E}$. $\mathrm{G}-\mathrm{C}$, in Victoria ward) was also a well-marked illustration of some of my preceding remarks, and of the precision given by the instrument. Suffering from chronic phthisis and occasional temporary loss of voice, and generally from hoarseness, the inference was natural that there was chronic laryngitis or ulceration of the interior of the larynx. But some of you will remember that we saw the vocal cords perfectly normal, but that the left one was rendered almost invisible by a considerable tumefaction of the mucous membraneof the correspond ing ventricle.

However, before speaking of laryngeal pathology as exhibited by the laryngoscope, let me say a few words anent the apparatus to be employed, the method of using it, and the points to be observed.

What do you want to do? In plain English, you want to look round a corner into a dark hole. This sounds paradoxical, but the paradox is solved by the laryngoscope.

The light either of the sun or of a lamp is received on a mirror attached to the observer's forehead, from which it is reflected on to a small mirror which is introduced into the fauces of the patient, and from this mirror again the light is thrown down upon and into the larynx. The angle of incidence being equal to the angle of reflection, you have merely to place your mirrors in such a relation to one another as to secure the proper direction of the rays of light, and a perfect and distinct image of the parts illuminated will be visible on the small mirror.

The sun, at all events in London, cannot be relied upon at any hour of the day; and patients would not, even if the sun were always shining, present themselves when his rays penetrate 1 a given locality. We therefore find it much more convenient to trust to artificial light altogether, and accordingly have recourse to a gas moderator, or, as you see here, a paraffin oil lamp, which are not amenable to the caprices of the weather.

It is well to darken the room in which you make your examination; but even this is not absolutely necessary if the light is protected by a convex mirror on one side, and concentrated by one or more lenses on the other. Various complex apparatuses have been devised for the purpose of intensifying the light. What you see here is an arrangement for which I received the suggestion from my friend, Dr. Johnson, and which has been most satisfactorily executed by Messrs. Elliot and Co. The lanip is a paraffin oil lamp, which gives a brilliant white light; on one side is a convex mirror, which reflects the light upon the lens opposite to it, and this, an ordinary bull's eye, concentrates the light upon the reflector. The lamp should be placed close to the patient's head, on either side most convenient to the observer, and so that the lamp and the patient's and observer's heads are in the same horizontal plane. The patient, sitting erect, should push his head back so as to straighten the neck and facilitate the introduction of the small mirror.

Before attempting to do this, the observer should first ascertain that the reflector is properly adjusted. If he finds that the mouth is fully illuminated, he may fairly conclude that he will be able to throw the light upon the fauces. Beginners generally find a little difficulty in adjusting the reflector, but this is speedily surmounted. Whether you place your mirror on your forehead, as recommended by Dr. Johnson, or whether you prefer to use it as I generally do, is a matter of little moment. Try both ways, and adopt the one you like best. The mirror I employ has, as you perceive, a central uncovered spot. It is an improvement upon the original mirror employed by the father of laryngoscopy, Professor Czermak, of which I show you a specimen. The one I recommend has a small universal joint, and, being placed a little distance from the eye, is much easier of adjustment. I admit that with Professor Czermak's instrument $I$ had a difficulty in seeing through the central orifice. but with this modification $I$ find it advantageous first to adjust the reflector so that $I$ am enabled to see the fauces through the opening with the eye covered with the reflector, and then $I$ am certain to have the proper axis for both eyes. After you have satished yourselves that the lamp and the reHector (which is fixed on the head by an elastic band passing over the forehead) are in the right position, tell your patient to open his month widely, to protrude the tongue, and to breathe freely. Some patients will permit you to see into their larynx without in any way fixing the tongue, but this is the exception. As a rule, it is necessary that the patient, or the observer, should take hold of the tip of the tongue with a handkerchief or towel, to prevent this " unruly organ" from slipping back. Without this precaution you very often fail in your endeavours to see below the epiglottis. Your next step, after having got your patient into the proper position, is to warm the laryngeal mirror. This is necessary, to prevent the vapour of respiration being precipitated on, and dimming the mirror; but take care not to overheat it. As a precaution, it is well to test the temperature by applying the back of the mirror to your own cheek.

Take hold of the stem of the mirror as if you were holding a pen; introduce it into the mouth without touching the tongue, teeth, or lips, sinking the hand at first, and then raising it gradually so as to allow the mirror to form a curve until it reaches the uvula. Almost the whole secret of the manipulation in laryngoscopy consists in this. If you touch the lips or teeth you teaze the patient, but if you touch the tongue you are certain to excite reflex action, and the root of the tongue will arch up to impede your view. Audacem fortuna juvat. Push your mirror, after having passed the janitors, well against the uvula, and you will rarely meet with any serious impediment in getting a proper view of the larynx. An unsteady hand creates difficulties which need not exist, by bringing the mirror into contact with other parts than the uvula and soft palate. 'These are not very sensitive, but if you tease the root of the tongue or the arches of the palate, you infallibly excite reflex action, which will necessitate the withdrawal of the instrument. Having placed your mirror at an angle of about $45^{\circ}$ with the horizon, it is well to rest the little finger of the right hand against the patient's cheek, by which means you will steady the instrument. You then secure a proper illumination of the laryngeal mirror, and by the necessary manipulation, which practice alone ean teach, you successively examine all the parts exposed to view.

In making the examination and recording the facts observed, you must remember that you are looking into a mirror, which represents the parts in a different relation from their real position. The epiglottis, which in nature is turned from the observer, is represented as opening towards him; the base of the tongue, which is in front of the epiglottis, appears in the mirror behind it; and the vocal cords equally occupy in the mirror a reversed position from that which they really possess. As laryngoscopic illustrations represent the appearances as seen in the mirror, it is necessary to remember the true relation in order to understand the drawing correctly. The lateral relations will cause less difficulty than the antero-posterior relations. What ordinarily appears to our left or right in the subject of observation placed before us, still continues so. We readily make the necessary allowances here from the habit engendered by custom; but it is different in regard to objects placed in front of each other and reflected in a mirror, because for this our daily life offers us fewer precedents. Perhaps the easiest way to realise the position of the parts as seen in the mirror is to imagine yourselves looking at the epiglottis and vocal cords through a hole in the cervical portion of the ver. tebral column. These points will become more apparent if we briefly examine the diagrams and preparations which I have placed before you. To the beginner I would say, Make your first experiment upon a case in which you are informed there is no special difficulty; remember the rules laid down; bear in mind the anatomy of the parts and the direction in which you wish to carry the light; and, with a light and steady hand, you will scarcely fail after one or two attempts, to see that which is ordinarily visible by the aid of this instrument.

Now, what are you to look for? The first point that always attracts the attention of the observer, after having got the light and the mirror duly placed, is the epiglottis. It is the Gape of Good Hope of the laryngoscopists, and it is at times a difficult matter, a very difficult matter, to round the Cape. You will find that it varies as much in form as the nose, and its position not unfrequently is so prone as to render a good view of the subjacent parts almost an impossibility. Then, too, in irritable persons it undergoes a variety of contortions and contractions, which give it a character for muscularity greater than anatomists show it to possess. Still, as a rule, it serves merely as a landmark anatomically and pathologically anatomically, because its well-known relations tell you in what direction to look for more important organs; pathologically, because the appearance of the mucous membrane covering the epiglottis is often a valuable indication as to the state of the 
subjacent parts. Examine the epiglottis carefully, the form, the colour, the attachments. It should be perfectly smooth, of a pale, yellowish-rose hue, and symmetrical. Look at the fossa formed by the front of the epiglottis with the base of the tongue, and note the state of any secretions upon or near the epiglottis. In disease you will see its colour varying from the dull white of anæmia to every shade of uniform, or streaky and patchy redness. It may present ulcers of varying size and depth ; it may be deformed by old cicatrices or congenital malformation; tumefaction from inflammatory or cedematous thickening of the mucous and submucous layers may present itself; and it may exhibit extravasations of blood, or be more or less bathed in pus, or covered with a mucous secretion. Similar conditions may be discovered in the glotto-epiglottid fossa or on the glotto-epiglottid folds. In order to see the parts subjacent to the epiglottis, you will have to depress the handle of your mirror somewhat, so as successively to illuminate the posterior surface of the epiglottis ; the arytenoid cartilages, with the corpuscula Santorini and Wrisbergii; the superior thyro-arytenoid folds, or the false vocal cords, as they are also called ; and by turning the mirror laterally you will examine the right and left sides of the introitus laryngis, and especially the state of the ventricles of the larynx. These are cul-de-sacs intervening between the vocal cords proper and the superior thyro-arytenoid folds. The state of the ventricles has an important bearing on the production of the voice, inasmuch as their patulousness is essential to the free vibration of the vocal cords and the due production of voice. If the mucous membrane of the ventricles is swollen, the pitch and sonorousness of the voice is interfered with, and the more the pouch is obliterated the greater will be the interference with phonation. It is here that various secretions form and accumulate, and you will readily understand why these should more or less affect the voice, as they present obstacles to the passage of the air, or diminish the vibrations of the aërial pulse. If the secretions are viscid, you may at times be puzzled by strings of mucus extending across the entrance of the larynx, closely simulating the vocal cords themselves. Little patches of secretion may also simulate ulcers. The sponge or brush will readily remove such secretions, and show the condition of the subjacent membrane. The ventricle, moreover, as in the case of $\mathrm{E}$. Gwhom I have already exhibited to you, and whom you will have further opportunities of examining, are the frequent seat of morbid growths. All these points having been noted, you seek the vocal cords themselves.

In a healthy larynx the vocal cords stand out, with a clear pearly sheen which is peculiarly characteristic. Once seen, the appearance is not to be forgotten; and you will often, in doubtful cases of laryngeal disease, rejoice at recognising this striking feature, because it will prove that the most important part involved in phonation (so far as the larymx is concerned) is healthy. The vocal cords, or inferior thyro-arytenoid ligaments, are mainly composed of yellow elastic tissue, but are endowed with the most marvellous capability of minute vibratile adjustment, subject to the controlling power of the will, exercised through the arytenoid, thyro-arytenoid, cxico-arytenoid, and other muscles. It has been calculated that no less than one hundred muscles" are brought into action in the ordinary modulation of the voice, but the note which is uttered depends upon the exact degree of tension of two ligaments, at the utmost seven lines in length, $\nmid$ which is mainly determined by the two sets of muscles mentioned. You will have a measure of the minuteness of this adjustment when you reflect that a practised singer is eapable of uttering three hundred different notes at will, for each of which on this minute vibrating cord a different stop must be applied.

The vocal cords are covered with mucous membrane, distinguished from the mucons membrane of the rest of the larynx, which is ciliated, by being squamous. $\neq$ This mucous membrane overlies the elastic tissue of the cords, and is liable -though to a much less extent than the mucous membrane in the vicinity-to congestion and the various morbid changes which are seen in this tissue elsewhere. An accurate knowledge of the anatomy and physiology of the parts will enable you more fully to aporeeiate the importance of minute shades of difference in the appearance of the parts. A roughness of the surface or a discoloration which would lead to no palpable results elsewhere, here affects the comfort, the oceupation, the

* Article "Voice," in the Cyelopedia of Anatomy and Physiology. t The whole length of the aperture of the giottis when open is eleven lines, of which the posterior part between the arytenoid cartilages and their anterior process measures four, and the anterior part between the vocal cords life of the patient, and is therefore $\pi$ ell deserring the study of the rractitioner by any additional physical means that may be rilucel at our disposal. Here, too, we hare a good illustration of the difference between vital morbid conditions and the condition of the same parts as seen after death : a difference that you should always bear in mind, as you maj otherwise easily be misled into a wrong interpretation of the phenomena presented on the pest-mortem table. If you had merely seen the interior of a larynx remored from the body, you would scarcely anticipate the marked contrast that exists in life between the vocal cords and the adjacent parts, nor would it be possible satisfactorily to determine the mode in which the variations of sound are produced by the rocal cords. Yon will find that there was much uncertainty as to the theory to be adopted regarding vocalization even in Muller's time; and it was not until after the practical introduction of the laryngoscope by Czermak that the study beeame satisfactory and the conclusions definite. If $I$ name Czermak, it is not because I do not appreciate the labours of others in this field; but whatever others have done, he certain] las compelled us all, by the demonstration of the comparative facility of laryngoscopic examination, to make it a part of our medical studies.

It would be an injustice, in speaking of the subject, not to mention the name of M. Garcia, a well-known singer and amateur physiologist, who established by laryngoscopic examination much that is now known as to the physiolosy of the larynx before Czermak had made known his method; but the pearl that M. Garcia discovered was not appreciated by our profession, and therefore, so far as the medical world are concerned, laryngoscopy remained an unknowro quantity until the appearance of Czermak's monograph.

It is not my object at present to do more than to interest you in the practical employment of the laryngoscope in the recognition and treatment of disease; therefore I do not attempt to lay before you an account of laryngeal physiology-a branch of science which is capable of further development, and which some of yon may feel called upon to promote. Allow me yet to revert to a few points connected with the pathology of the larynx, to which I would draw your attention, as illustrating the value of this mode of investigating disease. The practical examination of the numerous cases that present them. selves in our hospital will serve to impress uron your memory and comprehension more vividly what I now merely show you veluti in speculo.

I have spoken of various morbid changes seen in or near the vocal cords, showing increased or diminished vascularity, congestive or cedematous sweiling, ulceration, cicatrices, growths, all of which I have myself seen. If you consider the muscular and nervous functions of the parts, you will expect to see these also materially affected by disease. The plus--evidenced by spasm-is not likely to be very visible, because it will not leave you time for anything but immediate action to relieve your patient; but the minus of paralytic conclitions is frequently observable in the irregular action or vant of action of one or both vocal cords. It is here that stimulation, and notably the direct application of galvanism, is often of palpable benefit. And you will not examine many larynges before you will satisfy yourselves of the perfect facility with which you may direct the galvanic current, as well as any other medicinal application, to any given part of the larynx. This of course can only be learned by practice, and when the patients are before you ; therefore I confine myself to exhibiting some of the apparatus suitable for topical applications, and leave the detail of treatment to clinical demonstration.

I have not, however, quite done yet. You may see further than the vocal cords. Their under surface can at present only be examined when there is a hole in the trachea, and at least one instructive instance is on record where this mode of exploration was practised with much benefit to the patient. But these are refinements of practice upon which it is unnecessary to dwell. I now merely speak of the ordinary employment of the laryngoscope, and $I$ wish to remind you, that having explored the entrance to the larynx and the rocal cords, you should examine, as far as may be, the trachea. It is generally easy to recognise several rings of this tube, and you may, when the larynx is capacious and the patient steady, penetrate to the very bifurcation of the trachea. The only morbid condition that I have definitely recognised in the trachea have been scattered ulcers; but it is manifest that, especially in those cases in which foreign bodies have slipped through the glottis, the discovery of their exact site by the laryngoscope may, as it already has been, prove of great practical value to the surgeon.

There is no better mode of initiating yourselves into the practice of iaryngoscopy than to examine your own larynges, 
or those of your fellow-students. By this kind of exercitation you will familiarize yourselves with the use of the instrument no less than with the healthy condition of the parts. M. Garcia's interesting observations were entirely the result of examination made upon his own rocal cords, and as there is room for a further cultivation of this field of physiology, each of you may be enabled to advance science in this direction. But apart from this, the mere dexterity of manipulation will be increased by the practice recommended, and if you know from experience in your own persons how to behave, you will more readily advise your patients what to do, and sympathize with their difficulties. Not every one, however, is a suitable subject for autolaryngoscopy: the narrowness of the introitus laryngis and the prone position of the epiglottis, no less than an unusual irritability of the parts, frequently render the process extremely difficult. Various methods have been suggested for the removal of undue irritability, such as the inhalation of small quantities of chloroform, the application of bromide of potassium, or the use of astringent gargles. Every now and then, even after you have acquired sufficient dexterity in the use of the instrument, you will meet with cases which present insuperable difficulties. You are then no worse off than your predecessors were without the laryngoscope. You will have to fall back upon those other symptoms which your knowledge of physiology and pathology will teach you to appreciate, and which this instrument is not intended to supersede.

With these remarks I must conclude. Pray do not imagine that I have exhausted the subject. I have merely tried to put before you evidence to convince you that laryngoscopy merits your serious attention, whether you regard it as a means calculated to advance physiology, pathology, or therapeutics. It has, as I said in my opening remarks, helped to remove one more of the opprobria medicince, and to substitute for the guesses of the dogmatist the clearer light of positive demonstration. That an improved diagnosis ensures better treatment is self-evident, but a hope that we may have many opportunities in the wards of testing this proposition to our own satisfaction, no less than to that of our patients."

ON

\section{EXCISION OF THE WRIST FOR CARIES.}

BY JOSEPH LISTER, EsQ., F.R.S.,

PROFESSOR OF SURGERT IN THE VNIVERSITY OF GLASGOW. (Concluded from page 338.)

ONE or more sinuses may remain open for a long time, just as after excision of the elbow-joint, without anything being wrong with the bones; as, for example, in the case of Margaret W- - (Case 2), in which they did not finally close for more than a year after the operation. Or, again, the persistence of sinuses may depend upon small exfoliations, and these may prove extremely slow in separating. This may be illustrated by

CAsE 7, that of James $\mathrm{M}^{\prime} \mathrm{G}$ - _.., sixteen years of age, whose right wrist $I$ excised on the 21 st November, 1863, on account of disease of spontaneous origin, which had attained to much the same exaggerated degree as in Helen M- (Case 4), and presented similar apparently hopeless appearances: the hand, greatly swollen and discoloured, and with numerous sinuses and a gray palmar sore, hanging helpless at an angle of about sixty degrees, with the fingers stiff and clawed. The radius and ulna were very freely resected, and it was necessary to apply the gouge to the third and fourth metacarpal bones on account of extension of the disease below their bases. All went on well after the operation, except that a sinus remained in each line of incision, and a probe introduced into that on the ulnar side passed down to bare bone of irregular surface. This made me fear a return of the disease; but, as the wrist was growing firm and the hand useful, I did not interfere, and after the lapse of ten months a small exfoliation escaped from the ulnar aperture. The probe, being then introduced, no longer came in contact with any bone; and now, three months later, the sinus has become reduced to an almost invisible aperture, which yields only a minute drop of limpid liquid, while the new joint at the wrist is all that can be desired both in firmness and flexibility.

Hence so long as swelling and discharge diminish, and the

* At the conclusion of the Lecture Dr. Sieveking exhibited a variety of instruments employed for the treatment of diseases of the larynx.

strength of the hand increases, no interference is called for. But should the opposite conditions present themselves, recurrence of the disease must be suspected, and the part must be submitted to a thorough exploration, which should not be too long delayed, since caries re-appearing at a limited spot will spread in time to all the bones.

This course $I$ have found it necessary to adopt in more than one instance, as, for example, in the following case, which was in some respects the worst I have had to deal with.

CAsE 8.-Mrs. C-_ aged twenty-five, a marriel woman, came to the infirmary for the purpose of having her right hand amputated, on account of spontaneous disease of the carpus of two years' standing, attended for eighteen months with constant discharge, and for the last six months with such severe pain as to deprive her to a great extent of her nights' rest, while the effect upon her general health was marked by her wasted and sallow aspect, impaired appetite, and rapid pulse.

Some idea of the appearance of the wrist may be gathered from the accompanying illustration (Fig. 6), taken from a photograph, and also from the fact that the wrist measured nine inches and threequarters in circumference, whereas the sound one was slender both from natural conformation and from emaciation. The surface of the swollen part was studded with eight sinuses, through which the probe could be passed down to diseased bone in the forearm, the carpus, and the metacarpus. The hand drooped when the arm was extended, and the fingers were entirely useless. On the 8 th of June, 1864, I performed the operation, which proved very laborious on account of the condensation of the soft parts and the extraordinary enlargement of the radius from inflammatory hypertrophy, which made it impossible to protrude it as usual at the ulnar incision for the application of the saw, while its texture was so hard as to require considerable force with the most powerful cutting pliers to divide it.

For seven weeks all went on perfectly well, so that at the end of that time the circumference of the wrist was diminished by an inch, and she could readily pick up a light object with the finger and thumb of the unsupported hand, which drooped but slightly below the horizontal level. She was also quite free from uneasiness, and her general health was greatly improved. Unfortunately, however, the sores, which were previously healing kindly, were now attacked by hospital gangrene; and though this was checked in about five days by the application of nitric acid and other measures,

FIG. 6.

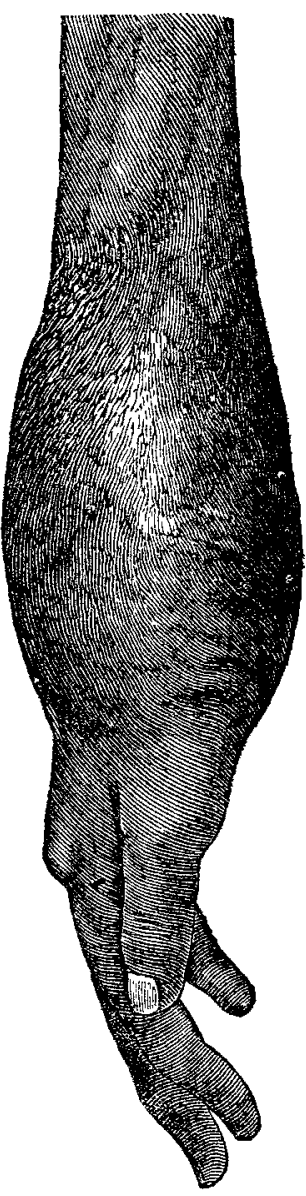

previously satisfactory progress was no longer observed and, when a month had elapsed without improrement, I resolved to investigate the cause. Having put her uncler the influence of chloroform, I opened up the lime of the ulnar incision, and, finding the end of the ulna again carious, removed it with pliers; but was pleased to find, on introducing $m y$ tinger into the cavity that still existed, that the large cut surface of the radius was smoothly covered with granulations, as also were the ends of the metacarpal bones. I therefore brought the edges of the incision together by stitches, except a part suffcient for the escape of discharges, and placed the limb again upon the splint. From that time forth she has advanced satisfactorily; and when she last came from her native town to see me.(Dec. 1864), the discharge had almost entirely ceased, the swelling was greatly reduced, and although the end of the radius was still very large, and the wrist measured eight inches and a quarter in circumference, the border of the bone was to be felt immediately beneath integument of normal thickness and consistence, and the hand had a thoroughly natural appearance. She could extend it unsupportel without any droop, and even raise it above the level of the forearm by muscular effort. She had discarded the sling, and, by help of a light splint, found the hand of much use to her, the movements of the thumb and fingers being very satisfactory. In this case return of the disease appeared to be pro-
duced by an attack of hospital gangrene, and I am inclined 